\title{
Nicotine promotes lymph node metastasis and cetuximab resistance in head and neck squamous cell carcinoma
}

\author{
RIEKO SHIMIZU $^{1}$, SOICHIRO IBARAGI ${ }^{1,2}$, TAKANORI EGUCHI ${ }^{2,3}$, DAISUKE KUWAJIMA ${ }^{1}$, \\ SHINICHI KODAMA ${ }^{1}$, TAKASHI NISHIOKA ${ }^{4}$, TATSUO OKUI ${ }^{1}$, KYOICHI OBATA $^{1}$, \\ KIYOFUMI TAKABATAKE ${ }^{5}$, HOTAKA KAWAI ${ }^{5}$, KISHO ONO ${ }^{1,3}$, \\ KUNIAKI OKAMOTO $^{3}$, HITOSHI NAGATSUKA ${ }^{5}$ and AKIRA SASAKI $^{1}$ \\ ${ }^{1}$ Department of Oral and Maxillofacial Surgery, ${ }^{2}$ Advanced Research Center for Oral and Craniofacial Sciences \\ and ${ }^{3}$ Department of Dental Pharmacology, Okayama University Graduate School of Medicine, Dentistry, \\ and Pharmaceutical Sciences, Okayama 700-8525; ${ }^{4}$ Department of Oral Diagnosis, Tohoku University \\ Graduate School of Dentistry, Sendai $980-8575 ;{ }^{5}$ Department of Oral Pathology \\ and Medicine, Okayama University Graduate School of Medicine, Dentistry, \\ and Pharmaceutical Sciences, Okayama 700-8525, Japan
}

Received June 26, 2018; Accepted October 24, 2018

DOI: 10.3892/ijo.2018.4631

\begin{abstract}
Epidermal growth factor (EGF) is overexpressed in many cancers and is associated with worse prognosis. EGF binds to its cell surface receptor (EGFR), which induces EGFR phosphorylation. Phosphorylated EGFR (p-EGFR) is translocated into the nucleus, which increases cancer cell activity. Nicotine, which is one of the main components of tobacco, is absorbed through pulmonary alveoli and mucosal epithelia in the head and neck region by smoking and moves into the blood. Nicotine in blood binds to nicotinic acetylcholine receptor (nAChR) in the central nervous system and serves a crucial role in tobacco addiction. Although $\mathrm{nAChR}$ localization is thought to be limited in the nervous system, $\mathrm{nAChR}$ is present in a wide variety of non-neuronal cells, including cancer cells. Recent studies suggest that nicotine contributes to the metastasis and resistance to anti-cancer drugs of various cancer cells. However, it remains unknown whether head and neck squamous cell carcinoma (HNSCC) cells can utilize nicotine-nAChR signaling to metastasize and acquire resistance to anti-cancer drugs, even though the mucosal epithelia of the head and neck region are the primary sites of exposure to tobacco smoke. To the best of our knowledge, the present study is the first to demonstrate the role of nicotine in metastasis and anti-EGFR-therapy resistance of
\end{abstract}

Correspondence to: Dr Soichiro Ibaragi, Department of Oral and Maxillofacial Surgery, Okayama University Graduate School of Medicine, Dentistry, and Pharmaceutical Sciences, 2-5-1 Shikata-cho, Kita-ku, Okayama 700-8525, Japan

E-mail: sibaragi@md.okayama-u.ac.jp

Key words: nicotine, head and neck squamous cell carcinoma, lymph node metastasis, cetuximab
HNSCC. The present findings demonstrated that nicotine increased proliferation, migration, invasion, $\mathrm{p}$-EGFR nuclear translocation and protein kinase $\mathrm{B}(\mathrm{Akt})$ phosphorylation in HNSCC cells. It was also demonstrated that nicotine restored cetuximab-inhibited proliferation, migration and invasion of HNSCC cells. Finally, an in vivo experiment revealed that nicotine increased lymph node metastasis of xenografted tumors, whereas an nAChR inhibitor suppressed lymph node metastasis and p-EGFR nuclear localization of xenografted tumors. Taken together, these results demonstrated that nicotine induced nuclear accumulation of p-EGFR, and activation of Akt signaling. These signaling pathways elevated the activities of HNSCC cells, causing lymph node metastasis and serving a role in cetuximab resistance.

\section{Introduction}

Epidermal growth factor (EGF) was isolated from mouse submaxillary glands and demonstrated to promote incisor eruption and eyelid opening in newborn rodents (1). After EGF binds to its cell surface receptor (EGFR), EGFR undergoes dimerization, which in turn induces EGFR auto-phosphorylation (2). This auto-phosphorylation elicits downstream signal transduction cascades such as the phosphoinositide 3-kinase-pyruvate dehydrogenase kinase-protein kinase $\mathrm{B}$ (Akt) and RAF-mitogen-activated protein kinase kinase-extracellular signal-regulated kinase pathways, which promote cell survival and proliferation. Phosphorylated (p-)EGFR is translocated to the cytoplasm and degraded in lysosomes, which causes suppression of downstream signaling cascades in normal cells (2). However, in cancer cells, p-EGFR is accumulated in the nucleus, increasing cancer cell activity (3). EGFR is overexpressed in many cancers, including head and neck, breast, lung, colon, stomach, kidney, prostate and ovarian cancer, and is associated with worse outcome (4-6). An anti-EGFR monoclonal 
antibody, cetuximab, is the first molecular target drug for head and neck squamous cell carcinoma (HNSCC) $(7,8)$. When combined with radiotherapy and chemotherapy, cetuximab has been demonstrated to have significant survival benefits in patients with locally advanced and recurrent/metastatic HNSCC, respectively $(7,8)$. However, resistance to cetuximab is known to develop gradually (9), and presents an important challenge for the future.

Tobacco smoking is associated with the carcinogenesis and development of cancer (10). Tobacco smoking is carcinogenic to the oral cavity, pharynx, larynx, esophagus, stomach, colon, liver, pancreas, lung, uterine cervix, ovary, kidney, renal pelvis and ureter, and bladder (10). The organs directly exposed to tobacco smoke are at high risk. Tobacco smoke is divided into a particle and gas phase (11). The particle phase includes tar and nicotine, while the gas phase includes carbon monoxide. Tar contains many carcinogenic chemicals, including benzopyrene and nitrosamine. Nicotine is responsible for tobacco addiction, and thus nicotine replacement therapy, which supplies nicotine in the form of gum or a patch, is used to help individuals with tobacco addiction quit smoking (12).

The nicotine in the tobacco smoke is absorbed across the epithelium of the lung, and the mucosal epithelia in the head and neck region, e.g., the oral cavity, nasal cavity, pharynx, nasopharynx and larynx (13). Nicotine exerts its cellular functions through nicotinic acetylcholine receptors (nAChRs). $\mathrm{nAChRs}$ are homomeric or heteromeric pentameric proteins consisting of $\alpha 1-10, \beta 1-4, \gamma, \delta$ and $\varepsilon$ subunits, and are located in the central nervous system and neuromuscular junctions (14). The binding of nicotine to $\mathrm{nAChRs}$ in the ventral tegmental area of the midbrain induces the release of dopamine to the nucleus accumbens, which is involved in the rewarding effects of nicotine and nicotine addiction. Although $\mathrm{nAChR}$ localization is thought to be limited in the nervous system, $\mathrm{nAChR}$ is present in a wide variety of non-neuronal cells, including bronchial epithelial, urothelial, skin, endothelial and vascular smooth muscle cells (15). The mucosal epithelia of the head and neck region are the primary sites of exposure to tobacco smoke, and $\mathrm{nAChRs}$ have been observed in mucosal epithelial cells in these regions $(16,17)$. Previous studies have suggested that nAChRs are also present in lung cancer, breast cancer, pancreatic cancer, colon cancer and head and neck cancer cells $(15,18-21)$. In lung and breast cancer, nicotine has been demonstrated to contribute to tumor growth and metastasis $(19,20)$. Nicotine also controls the expression and subcellular localization of EGFR in breast cancer cells (22). Specifically, nicotine decreases the expression of EGFR, and enhances the accumulation of p-EGFR in the nucleus, thereby increasing proliferation of breast cancer cells (22). Finally, in lung cancer cells, nicotine serves a role in the resistance against EGFR inhibitors $(23,24)$.

These facts prompted us to explore whether HNSCC cells could utilize nicotine-nAChR signaling to metastasize from the primary tumor to the regional lymph nodes and acquire resistance to cetuximab through EGFR activation. In the present study it was demonstrated that nicotine increased proliferation, migration, invasion, p-EGFR nuclear translocation and Akt activation in HNSCC cells. It was also demonstrated that nicotine restored cetuximab-inhibited proliferation, migration and invasion of HNSCC cells. Finally, it was demonstrated that an $\mathrm{nAChR}$ inhibitor suppressed lymph node metastasis in a mouse model of lymph node metastasis using OSC-19 cells.

\section{Materials and methods}

Cell culture and reagents. The following human HNSCC cell lines were used in the present experiments: HSC-2, a mouth floor SCC cell line derived from a metastatic cervical lymph node; HSC-3, a tongue SCC cell line derived from a metastatic cervical lymph node; OSC-19, a tongue SCC cell line derived from the primary site; and OSC-20, a tongue SCC cell line derived from a metastatic cervical lymph node. HSC-2 and HSC-3 were obtained from the Cell Engineering Division of the RIKEN BioResource Center (Ibaraki, Japan). OSC-19 and OSC-20 were obtained from the Health Science Research Resources Bank (Osaka, Japan). Human umbilical vein endothelial cells (HUVECs) were purchased from Takara Bio, Inc. (Otsu, Japan). All cancer cells were cultured in Dulbecco's modified Eagle's medium/Ham's F-12 nutrient mixture (DMEM/F-12: Gibco; Thermo Fisher Scientific, Inc., Waltham, MA, USA) supplemented with 10\% fetal bovine serum (FBS: Sigma-Aldrich; Merck KGaA, Darmstadt, Germany) at $37^{\circ} \mathrm{C}$. HUVECs were cultured in endothelial cell growth medium-2 (Takara Bio, Inc.) at $37^{\circ} \mathrm{C}$. Nicotine (Sigma-Aldrich; Merck KGaA; $0.5 \mu \mathrm{M})(19,20,22)$, mecamylamine hydrochloride (MCA; Sigma-Aldrich; Merck $\mathrm{KGaA} ; 50 \mathrm{nM}$ ) (22), $\alpha$-bungarotoxin ( $\alpha$-BTX; Abcam, Cambridge, UK; $1 \mu \mathrm{M}$ ) (17), cetuximab (Merck KGaA; $0.5 \mu \mathrm{g} / \mathrm{ml}$ ) (30), SCH772984 (Santa Cruz Biotechnology, Inc., Dallas, TX, USA; $1 \mu \mathrm{M}$ ) (25), Akt inhibitor II (Merck KGaA; $10 \mu \mathrm{M})(26)$ and temsirolimus (Pfizer, Inc., New York, NY, USA; $10 \mathrm{nM}$ ) (27) were purchased. The concentration of nicotine $(0.5 \mu \mathrm{M})$ used was decided based on previously published basic studies $(19,20,22)$ and clinical investigations in which the concentrations of nicotine in the bloodstream of smokers exposed to nicotine at pharmacological concentrations were reported to be $0.09-1 \mu \mathrm{M}(28,29)$.

Cell proliferation. Cells were seeded at a density of $1 \times 10^{5}$ cells in a 6-well plate. After becoming subconfluent at $37^{\circ} \mathrm{C}$, the cells were cultured for $24 \mathrm{~h}$ in DMEM/F-12 without FBS. They were then cultured in the presence or absence of nicotine $(0.5 \mu \mathrm{M})(19,20,22), \mathrm{MCA}(50 \mathrm{nM})(22), \alpha$-BTX $(1 \mu \mathrm{M})(17)$ or cetuximab $(0.5 \mu \mathrm{g} / \mathrm{ml})$ (30) in DMEM/F-12 supplemented with $0.5 \%$ FBS. The number of cells was counted with TC10TM automated cell counter (Bio-Rad Laboratories, Inc., Hercules, CA, USA) daily for 5 days.

Invasion and migration assays. Invasion and migration of cells were studied as reported previously, by using Boyden chambers with or without Matrigel ${ }^{\circledR}$, respectively (BD Biosciences, Franklin Lakes, NJ, USA) (31). Cells in the logarithmic growth phase were detached by trypsin-EDTA, and $3 \times 10^{4}$ cells in serum-free DMEM/F12 were added to polycarbonate membranes (pore size, $8.0 \mu \mathrm{m})$. Nicotine $(0.5 \mu \mathrm{M})$ was added to the lower chamber, and the system was incubated at $37^{\circ} \mathrm{C}$ for $24 \mathrm{~h}$ in $5 \% \mathrm{CO}_{2}$. Following incubation and fixation with $70 \%$ ethanol for $10 \mathrm{~min}$ at room temperature, the non-invading or migrating cells were removed with a cotton swab and 
the remaining cells were stained with $2 \%$ crystal violet (Sigma-Aldrich; Merck KGaA) for 5 min at room temperature. The number of stained cells on the lower side of the membrane in 4 light microscopic fields were counted, and the mean value of 3 wells was determined.

Immunoblot analysis. HSC-3 and OSC-19 cells were transferred to DMEM/F-12 without FBS, incubated for $24 \mathrm{~h}$, and then treated with nicotine $(0.5 \mu \mathrm{M})$ with or without MCA $(50 \mathrm{nM})$, $\alpha$-BTX $(1 \mu \mathrm{M})$, cetuximab $(0.5 \mu \mathrm{g} / \mathrm{ml}), \mathrm{SCH} 772984(1 \mu \mathrm{M})$, Akt inhibitor II $(10 \mu \mathrm{M})$ or temsirolimus $(10 \mathrm{nM})$ at $37^{\circ} \mathrm{C}$ for $1 \mathrm{~h}$. Cells in monolayer cultures were rinsed with ice-cold PBS and lysed in an ice-cold lysis buffer $(50 \mathrm{mM}$ Tris- $\mathrm{HCl}, \mathrm{pH} 7.4$, containing $150 \mathrm{mM} \mathrm{NaCl}, 1 \%$ Triton X-100, 1\% NP-40, $10 \mathrm{mM} \mathrm{NaF}$, $100 \mathrm{mM}$ leupeptin, $2 \mathrm{mg} / \mathrm{ml}$ aprotinin and $1 \mathrm{mM}$ phenylmethyl sulfonyl fluoride). Protein concentration was determined using a BCA Protein Assay Kit (Pierce, Thermo Fisher Scientific, Inc.) The cell lysates containing $10 \mu \mathrm{g}$ total protein in the lysis buffer were electrophoresed in $12 \%$ SDS-PAGE gels, and the proteins were then transferred to nylon membranes (Immobilon-P; EMD Millipore, Billerica, MA, USA). The membranes were blocked with $2 \%$ non-fat dry milk in TBS overnight at $4{ }^{\circ} \mathrm{C}$ and then incubated with a 1:1,000 dilution of the desired antibody at $4^{\circ} \mathrm{C}$ for $12 \mathrm{~h}$. Primary rabbit anti-human p-EGFR monoclonal immunoglobulin G (IgG; ab32578), mouse anti-human $\beta$-actin monoclonal IgG (ab49900), mouse anti-human PCNA monoclonal IgG (ab29; all Abcam), rabbit anti-human EGFR monoclonal IgG (4267S), rabbit anti-human p-Akt monoclonal IgG (4058), rabbit anti-human Akt monoclonal IgG (4685), rabbit anti-human p-mTOR polyclonal IgG (2974) and rabbit anti-human mTOR polyclonal IgG (2972; all Cell Signaling Technology, Danvers, MA, USA) were used for immunoblot analyses. Horseradish peroxidase (HRP)-conjugated goat anti-rabbit (RPN4301) or sheep anti-mouse IgG (NA931) were used as the secondary antibody at a 1:1,000 dilution (GE Healthcare Life Sciences, Little Chalfont, UK). Bands were visualized via enhanced chemiluminescence (RPN2109; GE Healthcare Life Sciences). Proteins in the nuclear and cytosolic fraction were obtained with NE-PERTM Nuclear and Cytoplasmic Extraction Reagents (Thermo Fisher Scientific, Inc.) using the experimental procedures specified by the manufacturer. For immunoblot analysis of $\alpha 7 \mathrm{nAChR}$, the cell lysates containing $40 \mu \mathrm{g}$ total protein in the lysis buffer were electrophoresed in $12 \%$ SDS-PAGE gels, and then the proteins were transferred to nylon membranes. The membranes were blocked with $2 \%$ non-fat dry milk in TBS overnight at $4^{\circ} \mathrm{C}$ and then incubated with a 1:400 dilution of rabbit anti-human $\alpha 7$ nAChR polyclonal IgG (ab10096; Abcam) overnight at $4^{\circ} \mathrm{C}$. HRP-conjugated goat anti-rabbit IgG (RPN4301) was used as the secondary antibody at a 1:10,000 dilution (GE Healthcare Life Sciences). Band densities of immunoblotting were quantified with ImageJ (version 1.51; National Institutes of Health, Bethesda, MD, USA).

Immunofluorescence staining. Following growth on culture slides, cells were washed with PBS, fixed at $-20^{\circ} \mathrm{C}$ for $20 \mathrm{~min}$ with $100 \%$ methanol, and permeabilized with $0.1 \%$ NP-40 in PBS. The slides were blocked with $3 \%$ FBS in PBS for 10 min at room temperature. Following washing 3 times with PBS, the cells were incubated for $1 \mathrm{~h}$ with 1:50 dilution of anti-p-EGFR (rabbit IgG; ab32578; Abcam) in 3\% BSA-PBS, washed 3 additional times with PBS, and reacted with 1:1,000 dilution of Alexa Fluor 647 (Invitrogen; Thermo Fisher Scientific, Inc.) in $3 \% \mathrm{BSA}-\mathrm{PBS}$ for $2 \mathrm{~h}$ at room temperature. Following a final wash, the cells were sealed with a coverslip and viewed under a fluorescent microscope (IX81; Olympus Corporation, Tokyo, Japan).

Lymph node metastasis model. All animal experiments were approved by the Institutional Animal Care and Use Committee of Okayama University (Okayama, Japan; OKU-2016046). The lymph node metastasis model was prepared as described previously (32). A total of 50 male athymic mice (nu/nu; age, 5 weeks; mean body weight, $19.5 \mathrm{~g}$ ) were obtained from CLEA Japan, Inc. (Tokyo, Japan). OSC-19 cells, $8 \times 10^{5}$ per mouse, were inoculated into a hind footpad. Groups of 10 mice each were peritoneally injected with either PBS, nicotine (30 $\mu \mathrm{g} / \mathrm{mouse})(20)$, MCA (20 $\mu \mathrm{g} / \mathrm{mouse})$ (33), nicotine and MCA, cetuximab (1 mg/mouse) (34), or cetuximab and nicotine every day. Tumor sizes and body weights were measured weekly, and the former were recorded in $\mathrm{mm}^{3}$ (length $\mathrm{x}$ width ${ }^{2} / 2$ ). Mice were sacrificed at day 42 , the footpad tumor tissues and popliteal lymph nodes were isolated and slides were prepared as described previously (32).

Immunohistochemistry for xenograft tumor specimens. Paraffin blocks of specimens were cut at $4-\mu \mathrm{m}$ thickness. The sections were deparaffinized, and then autoclaved in $0.2 \%$ citrate buffer for $15 \mathrm{~min}$ for antigen retrieval. Sections were incubated with $3 \%$ hydrogen peroxide for $30 \mathrm{~min}$ at room temperature to block endogenous peroxidase activity. Immunohistochemistry was performed using rabbit anti-human EGFR monoclonal IgG (Cell Signaling Technology, Inc.) and rabbit anti-human p-EGFR monoclonal IgG (Abcam), each at 1:100 dilution. The sections were incubated with the primary antibodies at $4^{\circ} \mathrm{C}$ for $16 \mathrm{~h}$, and then treated with Envision System Labeled Polymer (Dako; Agilent Technologies, Inc., Santa Clara, CA, USA) for $60 \mathrm{~min}$ at a dilution of 1:100. The immunoreaction was visualized using a 3,3'-diaminobenzidine substrate-chromogen solution. Finally, the sections were immersed in an ethanol and xylene bath and mounted for examination. The extent of p-EGFR staining was evaluated according to the percentage of cells with strongly stained nuclei in 3 visual fields under a light microscope (x200). All immunohistochemistry studies were evaluated by 2 experienced observers who were blind to the conditions of the experiments as reported previously (35).

Statistical analysis. Data were analyzed by using unpaired Student's t-test for analyses between two groups, and one-way analysis of variance with Bonferroni post hoc tests for the analysis of multiple group comparisons using SPSS statistical software (version 22; IBM Corp., Armonk, NY, USA). Results were expressed as the mean \pm standard deviation. To control for multiple testing for data in the incidence of popliteal lymph node metastasis in mice, q-values were calculated with the false discovery rate method controlled by the Benjamini-Hochberg procedure. $\mathrm{P}<0.05$ and $\mathrm{q}<0.05$ were considered to indicate statistically significant differences. 

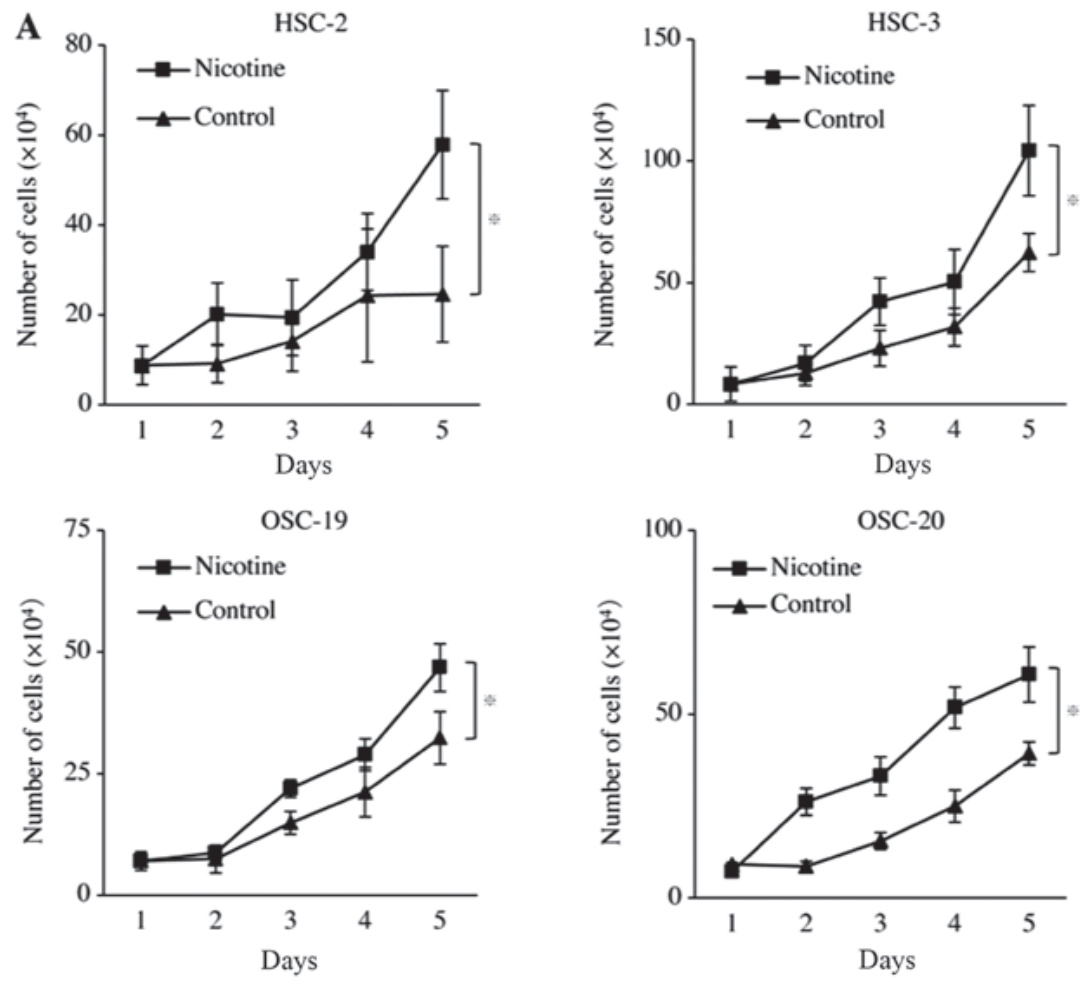

B

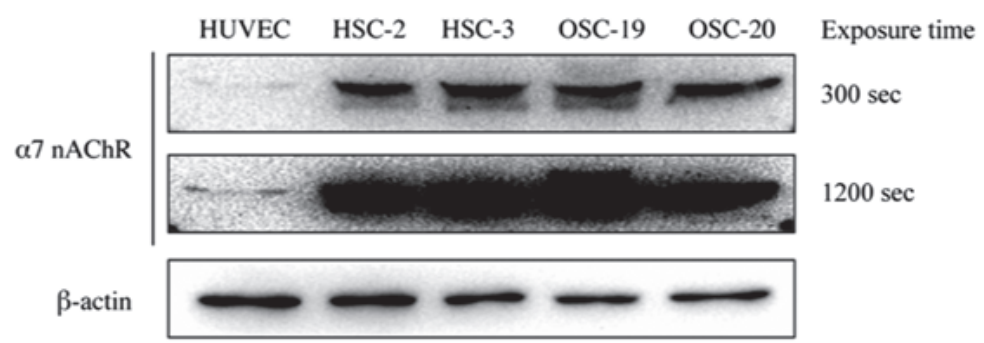

Figure 1. Effects of nicotine on the cell proliferation and expression of $\alpha 7 \mathrm{nAChR}$ of head and neck squamous cell carcinoma cells. (A) Proliferation. Cells were seeded at a density of $1 \times 10^{5}$ cells in a 6-well plate. After cells were attached to the plate, they were starved for $24 \mathrm{~h}$ in DMEM/F-12 without FBS. They were then cultured in the presence or absence of nicotine in DMEM/F-12 supplemented with 0.5\% FBS. All experiments were repeated 3 times. (B) Expression of $\alpha 7 \mathrm{nAChR}$ in HSC-2, HSC-3, OSC-19 and OSC-20 cells. HUVECs were used as a positive control of $\alpha 7 \mathrm{nAChR}$. Data are presented as the mean \pm standard deviation of triplicates from a typical experiment. ${ }^{*} \mathrm{P}<0.05 . \mathrm{nAChR}$, nicotinic acetylcholine receptor; DMEM/F-12, Dulbecco's modified Eagle's medium/Ham's F-12 nutrient mixture; FBS, fetal bovine serum; HUVEC, human umbilical vein endothelial cell.

\section{Results}

Nicotine upregulated HNSCC cell proliferation. To examine the effect of nicotine in vitro, HNSCC cells were treated with $0.5 \mu \mathrm{M}$ nicotine for 5 days. This treatment stimulated a $2.4-, 1.6-$, 1.5- or 1.6-fold increase in the proliferation of HSC-2, HSC-3, OSC-19 and OSC-20 cells at day 5, respectively (Fig. 1A). Having established that nicotine stimulated the proliferation of HNSCC cells, whether nicotine receptors were expressed in HNSCC cells was then examined. Among nicotinic acetylcholine receptors, $\alpha 7 \mathrm{nAChR}$ has been reported as the primary receptor that mediates the proliferative effects of nicotine in various cancer cells (18). In the present study, it was demonstrated that all four HNSCC cell lines exhibited stronger $\alpha 7 \mathrm{nAChR}$ expression than that of the HUVEC used as the positive control for $\alpha 7 \mathrm{nAChR}$ (Fig. 1B).

$n A C h R$ inhibitors suppressed nicotine-upregulated cell activities in HNSCC cells. As nicotine increased the cell proliferation of HNSCC cell lines, the effects of nAChR inhibitors on HNSCC cells were evaluated. As HSC-3 and OSC-19 have been reported to metastasize to the lymph nodes $(36,37)$, it was decided to use these cell lines in later experiments. HSC-3 and OSC-19 were treated with MCA (a non-selective nAChR inhibitor) and $\alpha$-BTX (an $\alpha 7 \mathrm{nAChR}$ inhibitor) in the presence of nicotine. Nicotine increased cell viability 1.3-fold in both HSC-3 and OSC-19 cells. MCA and $\alpha$-BTX inhibited nicotine-induced viability to the same level as in the control group (Fig. 2A). In regard to cell migration, nicotine increased cell migration 1.4- and 1.2-fold in HSC-3 and OSC-19 cells, respectively, and MCA and $\alpha$-BTX suppressed these nicotine-induced effects (Fig. 2B). Finally, invasion of HSC- 3 and OSC-19 cells was increased 1.4- and 1.3-fold by nicotine, respectively, and MCA and $\alpha$-BTX counteracted these effects as well (Fig. 2C).

Nicotine induced phosphorylation and nuclear translocation of EGFR. EGFR is known to be overexpressed and its signaling pathway is one of the most important pathways in HNSCC (3). As nicotine upregulated the cell activities of 
$\mathbf{A}$

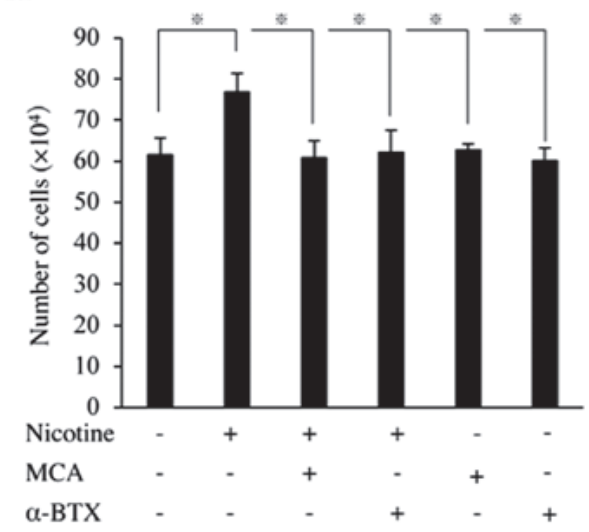

B

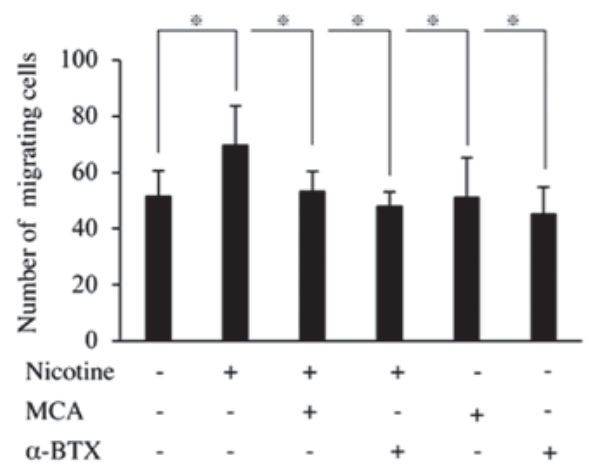

$\mathbf{C}$

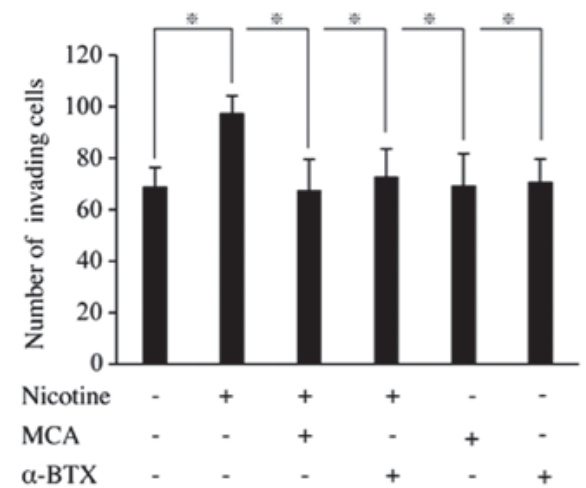

OSC-19

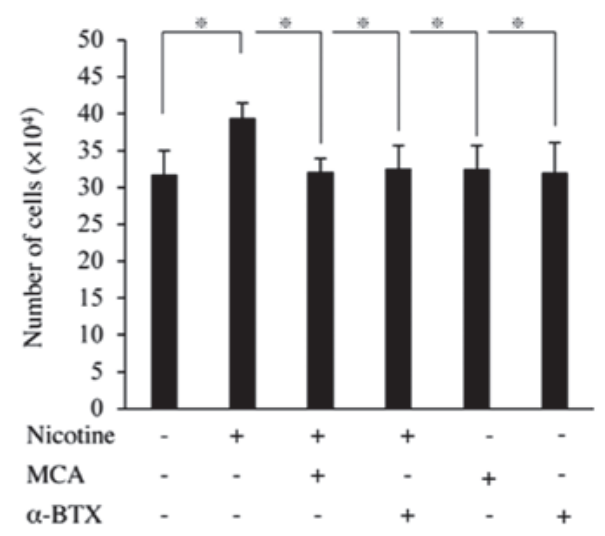

OSC-19

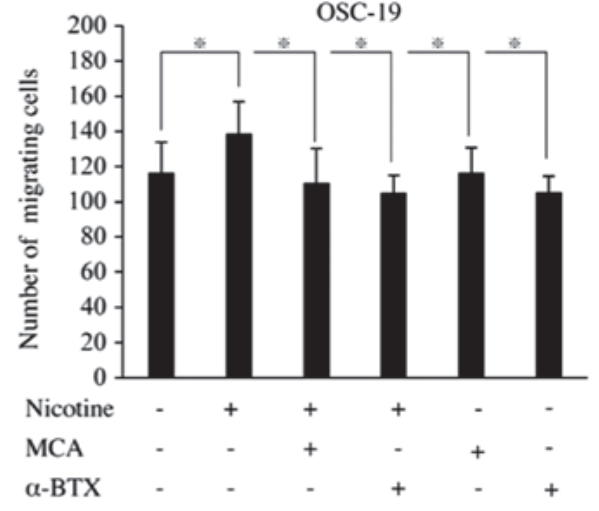

OSC-19

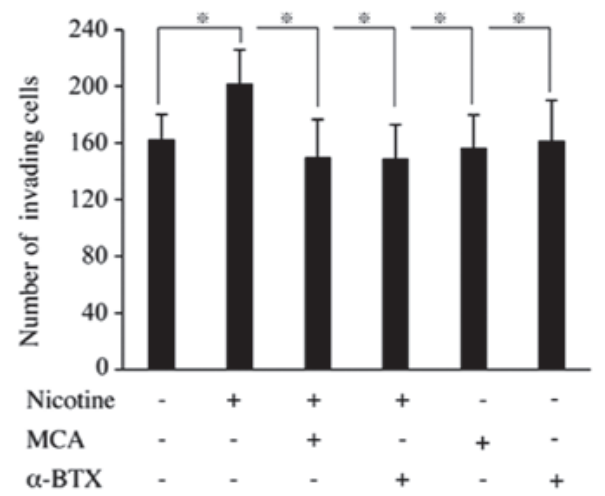

Figure 2. Effects of nAChR inhibitors on the cell viability, migration and invasion of HNSCC cells. (A) Viability. Cells were seeded at a density of $1 \times 10^{5}$ cells in a 6-well plate. After becoming subconfluent, cells were cultured for $24 \mathrm{~h}$ in DMEM/F-12 without FBS. They were then cultured in the presence or absence of nicotine, MCA or $\alpha$-BTX in DMEM/F-12 supplemented with $0.5 \%$ FBS. The cell number was measured at day 5. (B) Migration. Migration was evaluated using Boyden chambers. Cells were seeded at a density of $3 \times 10^{4}$ in medium with or without MCA, $\alpha$-BTX or cetuximab on polycarbonate membranes. Nicotine was added to the lower chamber, and the system was incubated for $24 \mathrm{~h}$. Following incubation, the number of cells on the lower side of the membrane was counted. (C) Invasion. Invasion was evaluated using Boyden chambers with Matrigel ${ }^{\circledR}$. Incubation and cell counting were performed as in the migration assay. All experiments were repeated 3 times. Data are presented as the mean \pm standard deviation of triplicates from a typical experiment. ${ }^{*} \mathrm{P}<0.05$. nAChR, nicotinic acetylcholine receptor; HNSCC, head and neck squamous cell carcinoma; DMEM/F-12, Dulbecco's modified Eagle's medium/Ham's F-12 nutrient mixture; FBS, fetal bovine serum; MCA, mecamylamine hydrochloride; $\alpha$-BTX, $\alpha$-bungarotoxin.

HNSCC in the present experiments, the effect of nicotine on EGFR activation was evaluated. It was demonstrated that both EGFR phosphorylation and Akt phosphorylation were increased $1 \mathrm{~h}$ following the addition of nicotine (Fig. 3A). Immunofluorescence analysis of HNSCC cells demonstrated that nicotine induced p-EGFR nuclear translocation (Fig. 3B). To obtain quantitative data on this effect, p-EGFR distribution was evaluated in the nuclear and cytosolic fractions. Immunoblot analysis revealed an increase in nuclear p-EGFR in both HSC-3 (7.1-fold p-EGFR/EGFR and 1.4-fold p-EGFR/ $\beta$-actin) and OSC-19 (2.2-fold p-EGFR/EGFR and 1.6-fold p-EGFR/ $\beta$-actin) cells exposed to nicotine, respectively (Fig. 3C).

Nicotine induced phosphorylation of EGFR, Akt and mTOR through nAChRs. To determine whether nAChRs served any role in the activation of EGFR and Akt by nicotine, whether nAChR inhibitors would suppress the effects of nicotine 
A

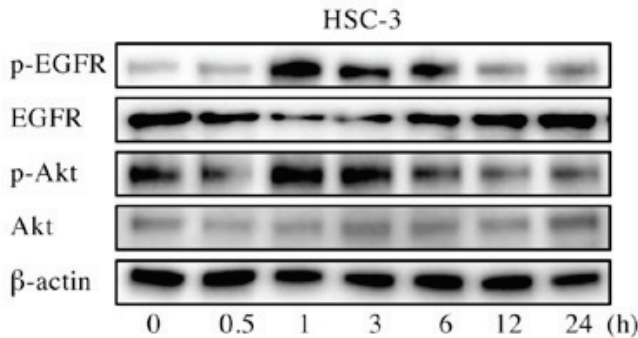

OSC- 19

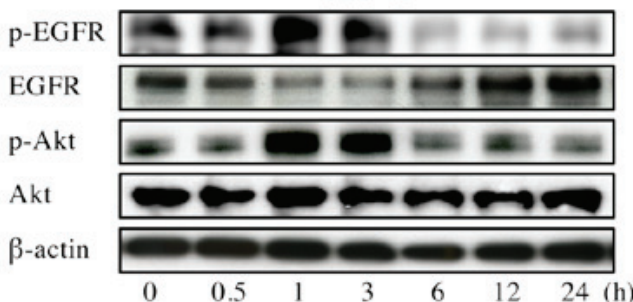

B

p-EGFR
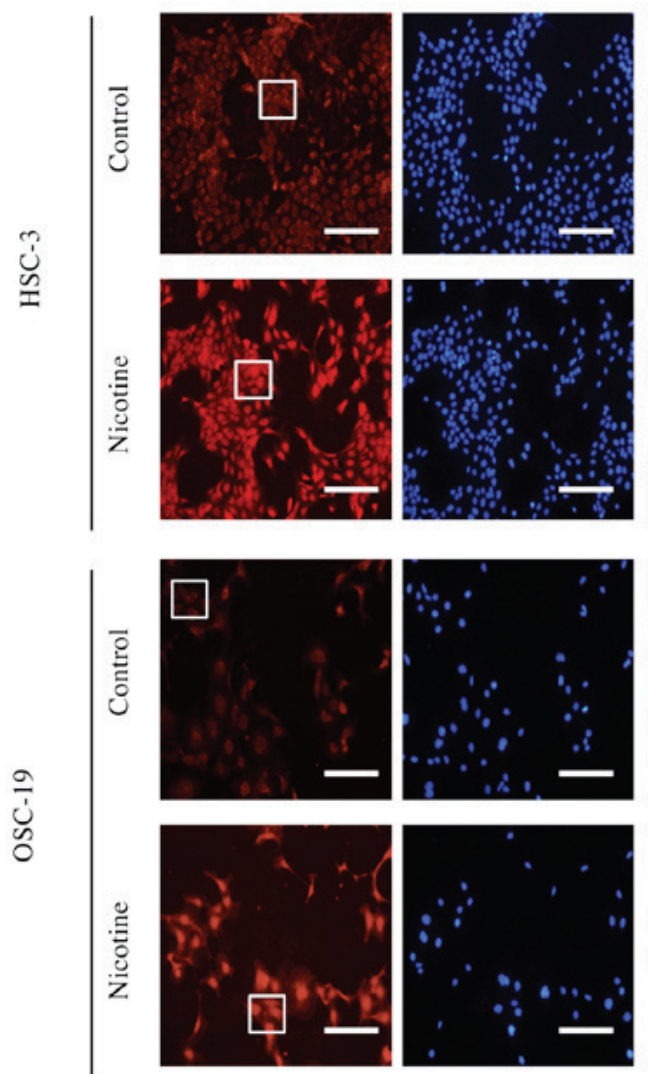

DAPI

Merged
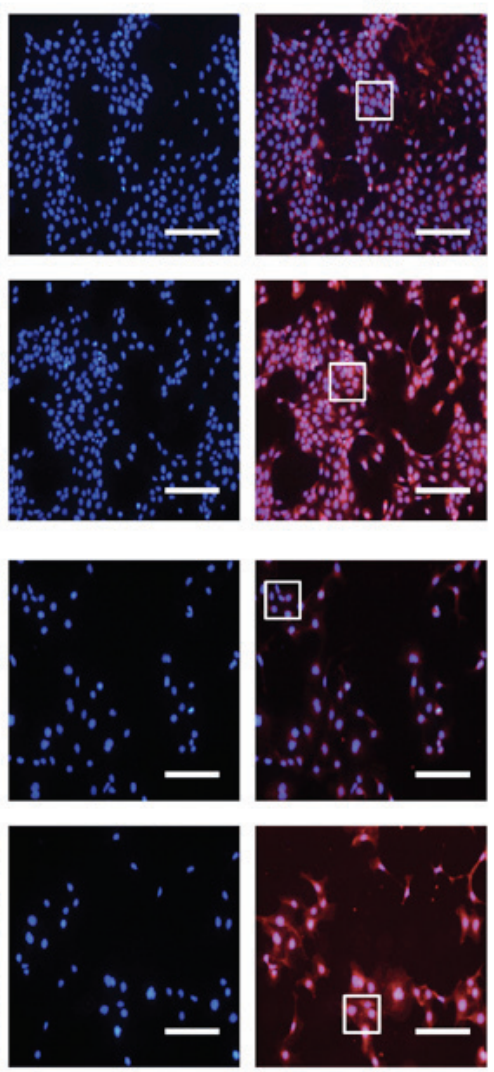

Insert $(\mathrm{p}-\mathrm{EGFR})$
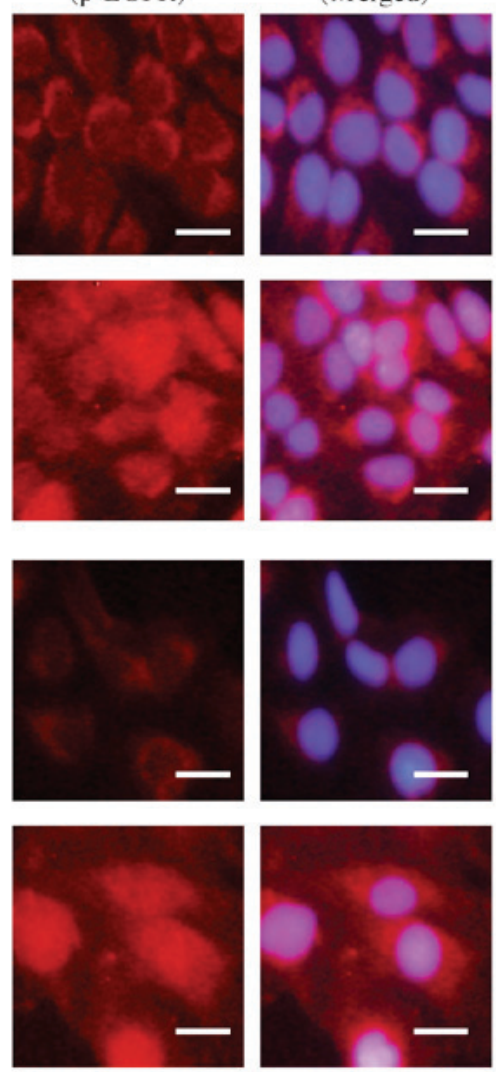

Insert

(Merged)
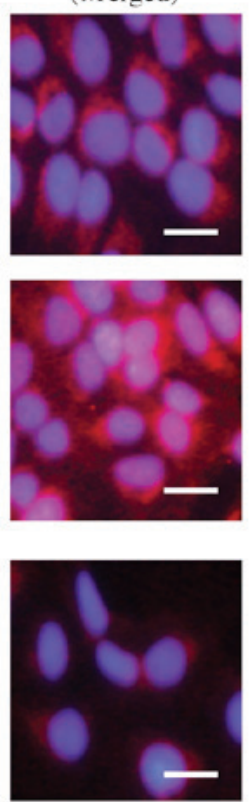

C

HSC-3

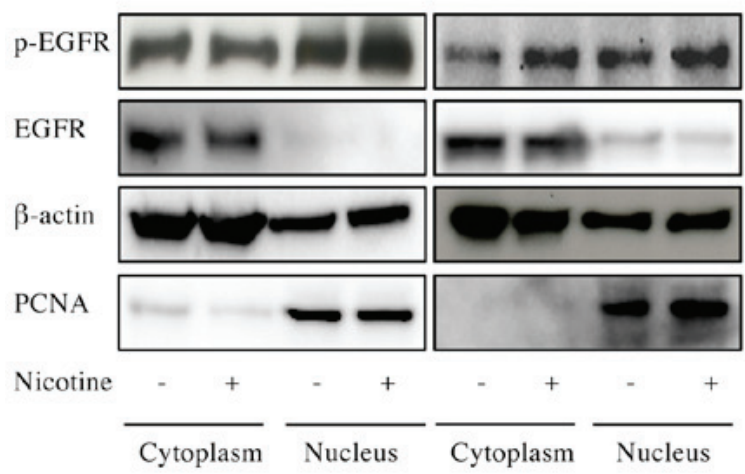

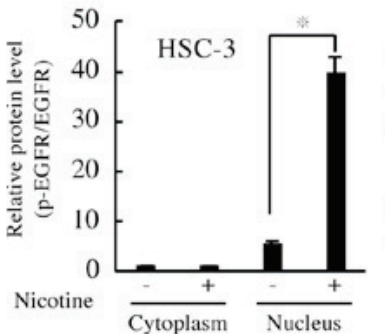
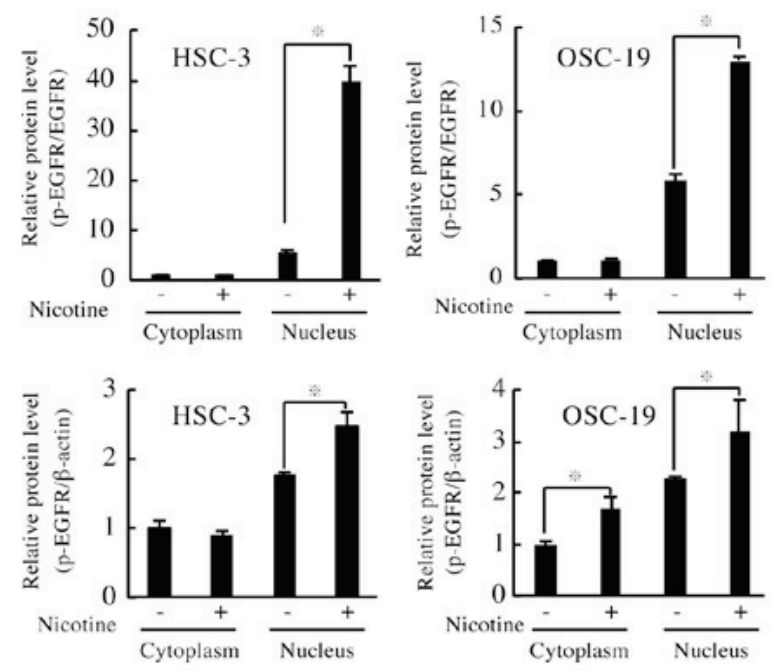

Figure 3. Effect of nicotine on EGFR and Akt activation in head and neck squamous cell carcinoma cells. (A) HSC-3 and OSC-19 cells were treated with $0.5 \mu \mathrm{M}$ nicotine for the indicated times, and cell layer extracts were then analyzed by immunoblotting with antibodies recognizing p-EGFR and p-Akt. (B) Cells were immunostained for the intracellular distribution analysis of p-EGFR in untreated and nicotine-treated cells. Nicotine induced p-EGFR nuclear translocation in both HSC-3 and OSC-19 cells. DAPI was used for nuclear staining. Scale bar, $200 \mu \mathrm{m}$. The merged, p-EGFR and DAPI images were merged. The insert presents high magnification images of the indicated areas of p-EGFR or merged. Scale bar, $30 \mu \mathrm{m}$. (C) Harvest cells were sub-fractionated into cytoplasmic and nuclear fractions and processed for immunoblot analysis of p-EGFR. $\beta$-actin and PCNA were loading controls. Bar charts present the relative protein levels of p-EGFR/EGFR and p-EGFR/ $\beta$-actin in HSC-3 and OSC-19 cells. Data are presented as the mean \pm standard deviation. "P<0.05. EGFR, epidermal growth factor receptor; Akt, protein kinase B; p, phosphorylated. 
A

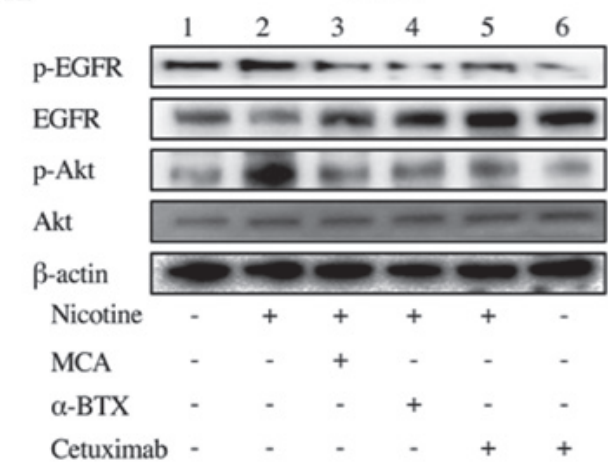

B

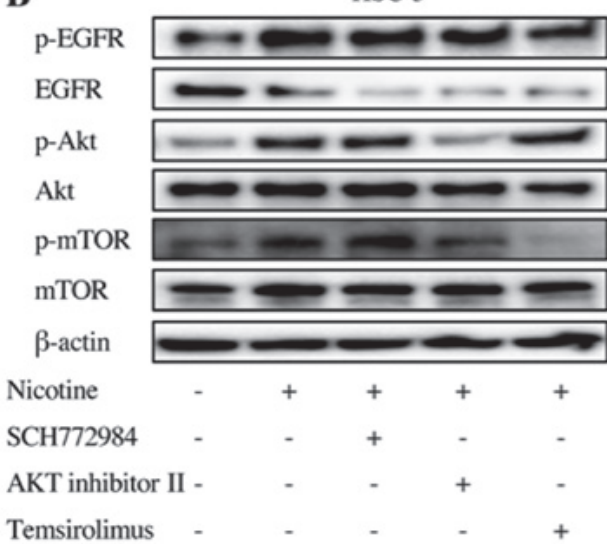

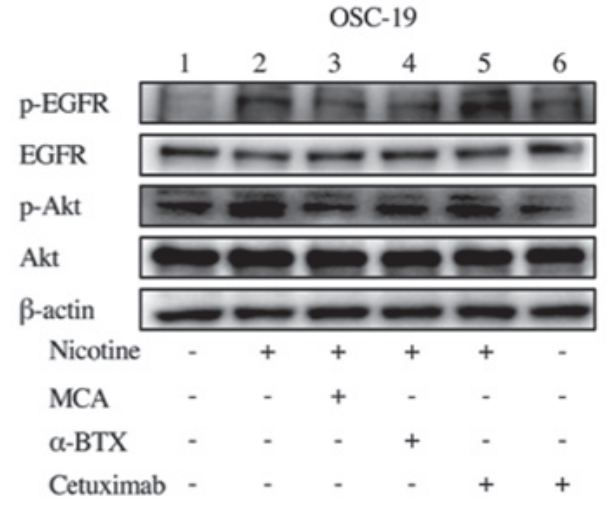

OSC-19

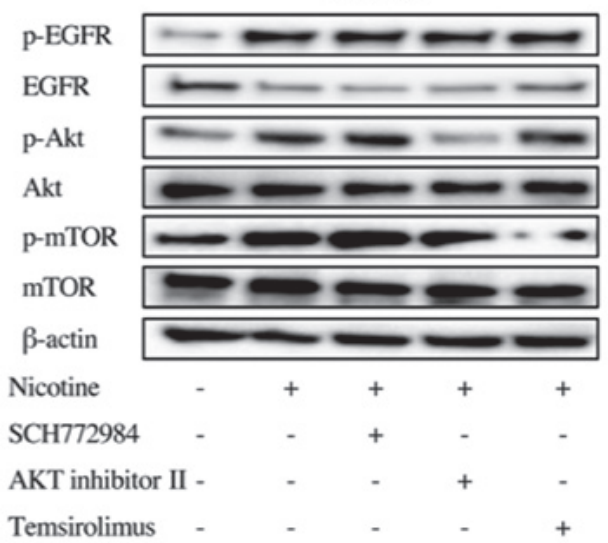

Figure 4. Effects of MCA, $\alpha$-BTX, cetuximab, SCH772984, Akt inhibitor II and temsirolimus on nicotine-dependent activation of EGFR, Akt and mTOR in head and neck squamous cell carcinoma cells. (A) Nicotinic acetylcholine receptor; downstream signaling. HSC-3 and OSC-19 cells were transferred to DMEM/F-12 without FBS, incubated for $24 \mathrm{~h}$, and then treated with $0.5 \mu \mathrm{M}$ nicotine with or without MCA, $\alpha$-BTX or cetuximab for $1 \mathrm{~h}$. Protein extracts were analyzed by immunoblotting with antibodies recognizing p-EGFR and p-Akt. (B) EGFR downstream signaling. Cancer cells were transferred to DMEM/F-12 without FBS, incubated for $24 \mathrm{~h}$, and then treated with nicotine with or without SCH772984, Akt inhibitor II or temsirolimus at $37^{\circ} \mathrm{C}$ for $1 \mathrm{~h}$. Protein extracts were analyzed by immunoblotting with antibodies recognizing p-EGFR, p-Akt and p-mTOR. MCA, mecamylamine hydrochloride; $\alpha$-BTX, $\alpha$-bungarotoxin; EGFR, epidermal growth factor receptor; Akt, protein kinase B; mTOR, mechanistic target of rapamycin; DMEM/F-12, Dulbecco's modified Eagle's medium/Ham's F-12 nutrient mixture; FBS, fetal bovine serum; p, phosphorylated.

was evaluated. Treatment with MCA and $\alpha$-BTX reversed the nicotine-induced activation of EGFR and Akt (Fig. 4A), suggesting that nicotine activates EGFR and Akt via nAChRs. To examine whether Akt and mTOR are involved in the region downstream of the nicotine-nAChR-EGFR pathway, Akt inhibitor II (an Akt inhibitor) and temsirolimus (an mTOR inhibitor) were used. Treatment with Akt inhibitor II reversed the nicotine-dependent stimulation of Akt and mTOR, whereas it did not change EGFR phosphorylation (Fig. 4B). In a similar manner, temsirolimus also markedly counteracted the nicotine-dependent stimulation of mTOR, whereas it did not change the levels of EGFR or Akt phosphorylation (Fig. 4B). SCH772984 (a MAPK inhibitor) did not change EGFR, Akt or mTOR phosphorylation (Fig. 4B). Taken together, our findings demonstrate that nicotine stimulated the EGFR-Akt-mTOR signaling pathway via nAChRs in HNSCC cells.

Notably, in lanes 5 and 6 of Fig. 4A, it was observed that nicotine upregulated cetuximab-suppressed EGFR phosphorylation, suggesting that nicotine may contribute to cetuximab resistance.

Nicotine counteracted the anti-tumor effects of cetuximab in HNSCC cells. As nicotine upregulated cetuximab-suppressed
EGFR phosphorylation, it was speculated that nicotine counteracted anti-EGFR therapy through EGFR activation. To test this hypothesis, HNSCC cells were treated with cetuximab and nicotine, then the cell activities were evaluated.

In the presence of cetuximab alone, the proliferation of HSC-3 and OSC-19 cells was significantly inhibited. When nicotine was added, however, the proliferation of both HSC-3 and OSC-19 cells increased to 1.4-fold of that in the group treated with cetuximab alone (Fig. 5A). Cetuximab also significantly inhibited the cell migration of HNSCC cells. However, when nicotine was added, the cell migrations of HSC-3 and OSC-19 cells were increased to 1.7- and 1.3-fold of those in the cells treated with cetuximab alone (Fig. 5B). In a similar manner, the levels of invasion of HSC-3 and OSC-19 cells treated with cetuximab and nicotine were 1.9- and 1.6-fold of those in the cells treated with cetuximab alone, respectively.

An nAChR inhibitor suppressed the tumor growth and lymph node metastasis of xenografted HNSCC in athymic mice. To further investigate whether nicotine was responsible for tumor growth and metastasis by HNSCC cells, an animal model of lymph node metastasis was utilized (32). To inhibit nAChRs, only MCA was used in animal experiments. 
A

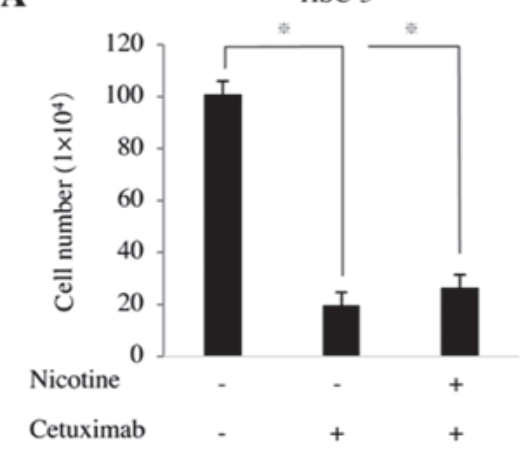

B

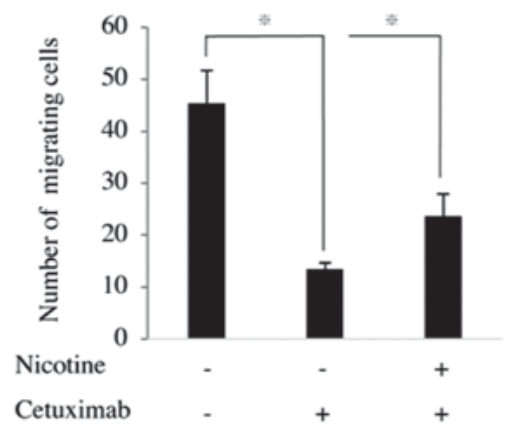

C

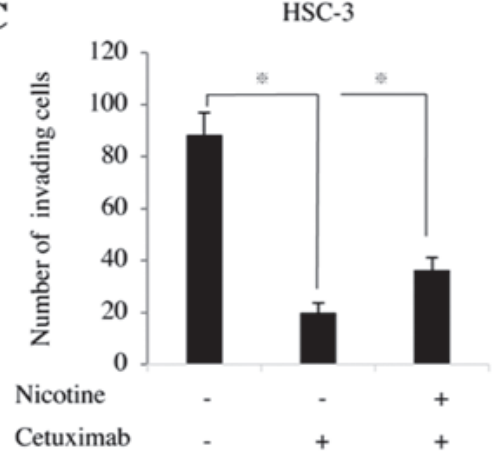

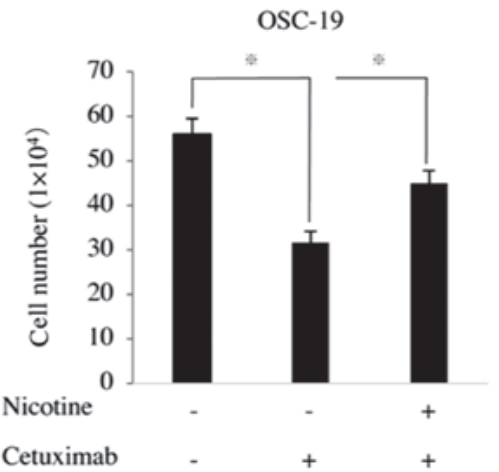
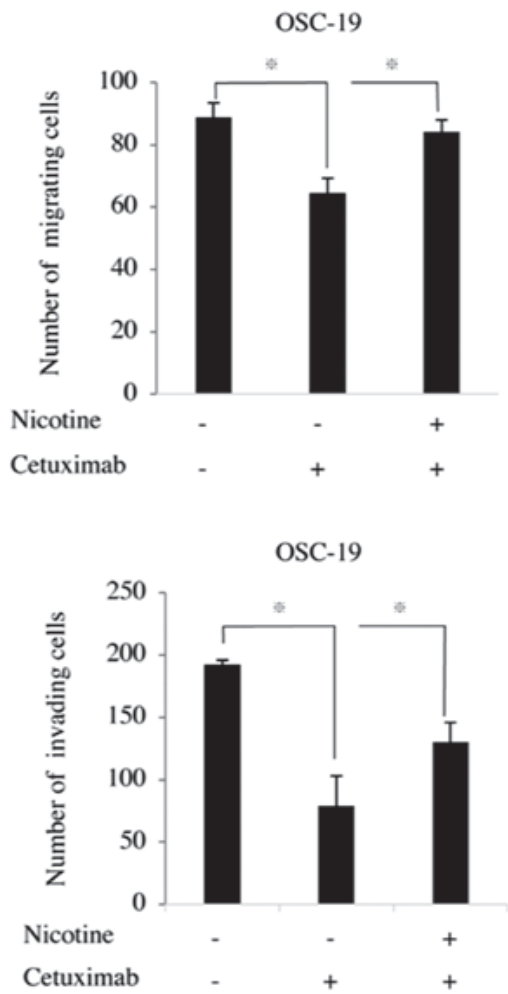

Figure 5. Effects of nicotine on cetuximab-suppressed viability, migration and invasion of head and neck squamous cell carcinoma cells. (A) Viability. Cells were seeded at a density of $1 \times 10^{5}$ cells in a 6 -well plate. After becoming subconfluent, cells were cultured for 24 h in Dulbecco's modified Eagle's medium/Ham's F-12 nutrient mixture without fetal bovine serum. They were treated with cetuximab for 30 min, and then cultured in the presence or absence of nicotine. The cell number was measured at day 6. (B) Migration. Migration was evaluated using Boyden chambers. Cells were seeded at a density of $3 \times 10^{4}$ in medium with cetuximab on polycarbonate membranes. Nicotine was added to the lower chamber, and the system was incubated for $24 \mathrm{~h}$. Following incubation, the number of cells on the lower side of the membrane was counted. (C) Invasion. Invasion was evaluated using Boyden chambers with Matrigel ${ }^{\circledR}$. Incubation and cell counting were performed as in the migration assay. All experiments were repeated 3 times. Data are presented as the mean \pm standard deviation of triplicates from a typical experiment. ${ }^{*} \mathrm{P}<0.05$.

MCA (38) is well-known as an antihypertensive drug under the name Inversine ${ }^{\circledR}(39)$, whereas $\alpha$-BTX is famous as a snake venom (40); therefore, MCA was speculated to be more suitable for future clinical application.

In the animal experiments, nicotine increased the growth rate of xenografted tumors compared with the rate in the control group, and MCA decreased tumor growth compared with the nicotine-treated group (Fig. 6A). The tumor volumes at the end of the experiment (day 42) for the control group, nicotine-treated group and MCA group were 615.2 \pm 65.3 , $950.0 \pm 188.9$ and $686.5 \pm 156.4 \mathrm{~mm}^{3}$, respectively. These results indicated an $\sim 54.5 \%$ increase in the tumor growth rate for the nicotine-treated group. The findings also suggested that MCA effectively inhibited the nicotine-induced xenograft tumor growth of HNSCC cells in athymic mice to the same level as in the control group (Fig. 6A). Furthermore, nicotine increased cetuximab-suppressed xenografted tumor grow th from $1.2 \pm 1.8$ to $32.9 \pm 37.7 \mathrm{~mm}^{3}$, suggesting that nicotine may contribute to local relapse following anti-EGFR therapy.

To determine whether nicotine influences p-EGFR localization in vivo, the percentage of p-EGFR-positive nuclei in the tumor specimens was evaluated. As presented in Fig. 6B, the percentage of p-EGFR-positive nuclei was increased in the nicotine-treated group $(57.7 \pm 8.4 \%)$ compared with the control group $(42.6 \pm 9.9 \%)$, which was consistent with the in vitro analysis. Conversely, MCA decreased the percentage of p-EGFR-positive nuclei to the level of the control group $(46.8 \pm 9.6 \%)$. Nicotine also increased the rate of popliteal lymph 
A
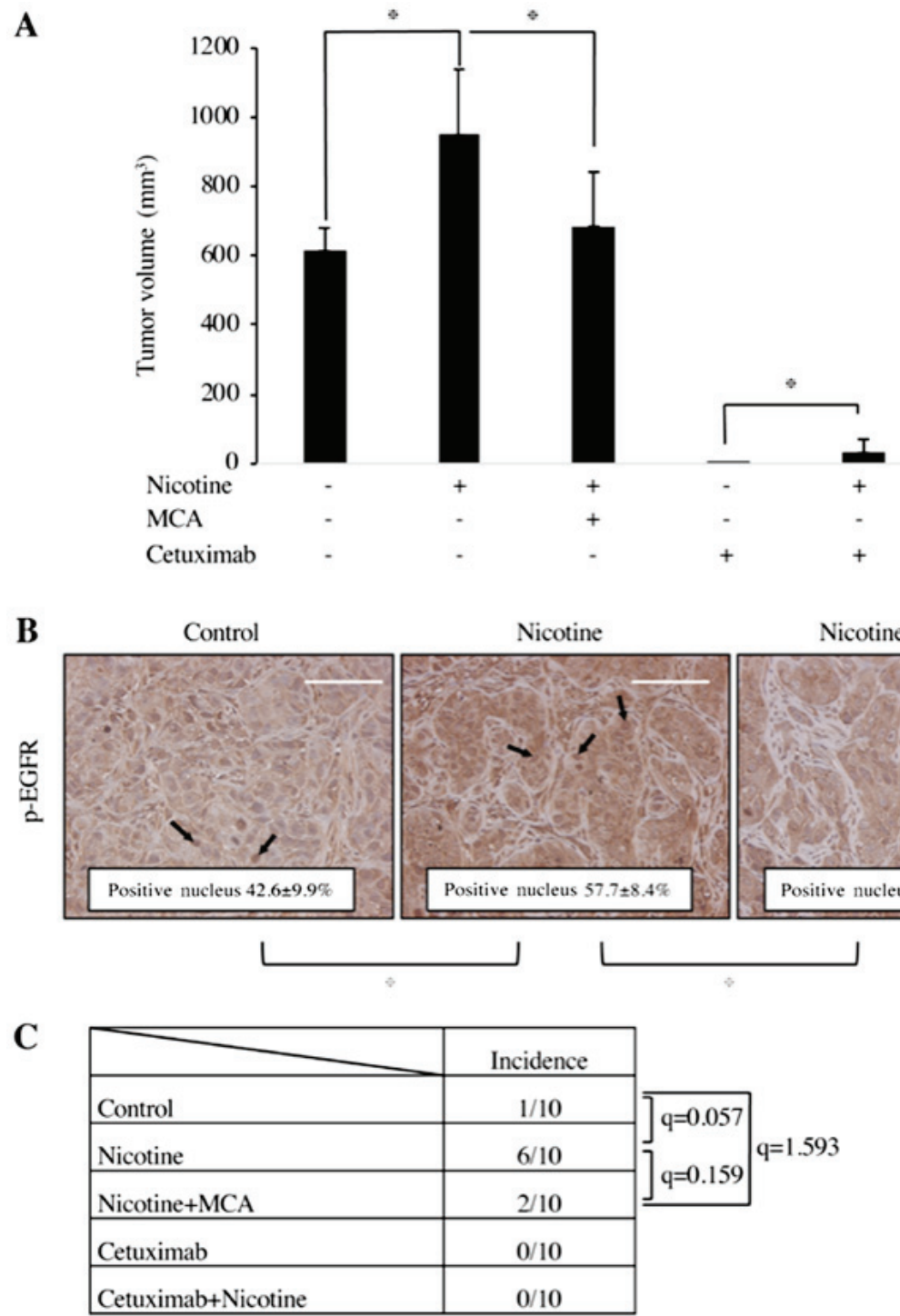

Figure 6. Effect of nicotine, MCA and cetuximab on the growth of OSC-19 xenografts and lymph node metastasis in athymic mice. (A) A total of $8 \times 10^{5}$ OSC- 19 cells per mouse (10 mice/group) were inoculated into the hind footpad of athymic mice. Mice were peritoneally administered with PBS, nicotine (30 $\mu \mathrm{g} / \mathrm{mouse})$, MCA (20 $\mu \mathrm{g} / \mathrm{mouse})$, nicotine and MCA, cetuximab (1 mg/mouse), or cetuximab and nicotine every day. Mice were sacrificed at day 42. In bar chart, the data are presented as tumor volume in $\mathrm{mm}^{3}$ (length $\mathrm{x}$ width ${ }^{2} / 2$ ). Data are presented as the mean \pm standard deviation. ${ }^{*} \mathrm{P}<0.05$. (B) IHC staining of OSC-19 xenograft tumor specimens from the hind footpad. IHC staining of EGFR and p-EGFR in tumors from the OSC-19 treated with or without nicotine or MCA is presented. Nicotine induced nuclear localization of p-EGFR (arrows) whereas MCA suppressed nicotine-induced nuclear localization of p-EGFR. Scale bar, $100 \mu \mathrm{m}$. (C) The rate of popliteal lymph node metastasis is presented as the number of mice with metastases/number of mice injected. Lymph node metastasis was observed in the control group (10\%), nicotine-treated group (60\%) and nicotine and MCA-treated group (20\%). MCA, mecamylamine hydrochloride; IHC, immunohistochemical; EGFR, epidermal growth factor receptor; p, phosphorylated.

node metastasis from 10 to $60 \%$. MCA decreased the rate of metastasis to $20 \%$. Although there were no significant differences between the any two groups, there was a trend toward higher metastasis rate with nicotine compared with control. (control vs. nicotine, $\mathrm{q}=0.057$; nicotine vs. nicotine $+\mathrm{MCA}$, $\mathrm{q}=0.159$; nicotine + MCA vs. control, $\mathrm{q}=1.593$; Fig. 6 C). There was no lymph node metastasis in either the cetuximab-treated group or the cetuximab and nicotine-treated group.

Taken together, the in vivo experiments revealed that nicotine increased the tumor growth and lymph node metastasis of HNSCC, whereas MCA suppressed them. It was also demonstrated that nicotine restored the cetuximab-inhibited tumor growth of HNSCC. The activation and nuclear localization of EGFR may contribute to these tumor-promoting effects of nicotine.

\section{Discussion}

Nicotine, one of the crucial components in the addictiveness of tobacco, also has important roles in the invasion and metastasis of various cancers, including lung cancer, breast cancer, glioma, bladder cancer, pheochromocytoma and colorectal cancer $(15,18)$. In lung cancer cells, nicotine exposure induces epithelial-mesenchymal transition (41). In breast cancer cells, nicotine promotes cell motility via PKC and cdc 42 , leading to lung metastasis (20). However, its effect in HNSCC cells is unknown. To determine whether nicotine influences HNSCC in vivo, a mouse model of lymphatic metastasis was prepared (32). In this model, nicotine increased the tumor volume and incidence of metastasis in regional lymph nodes compared with the control groups. Consistent with the in vivo 


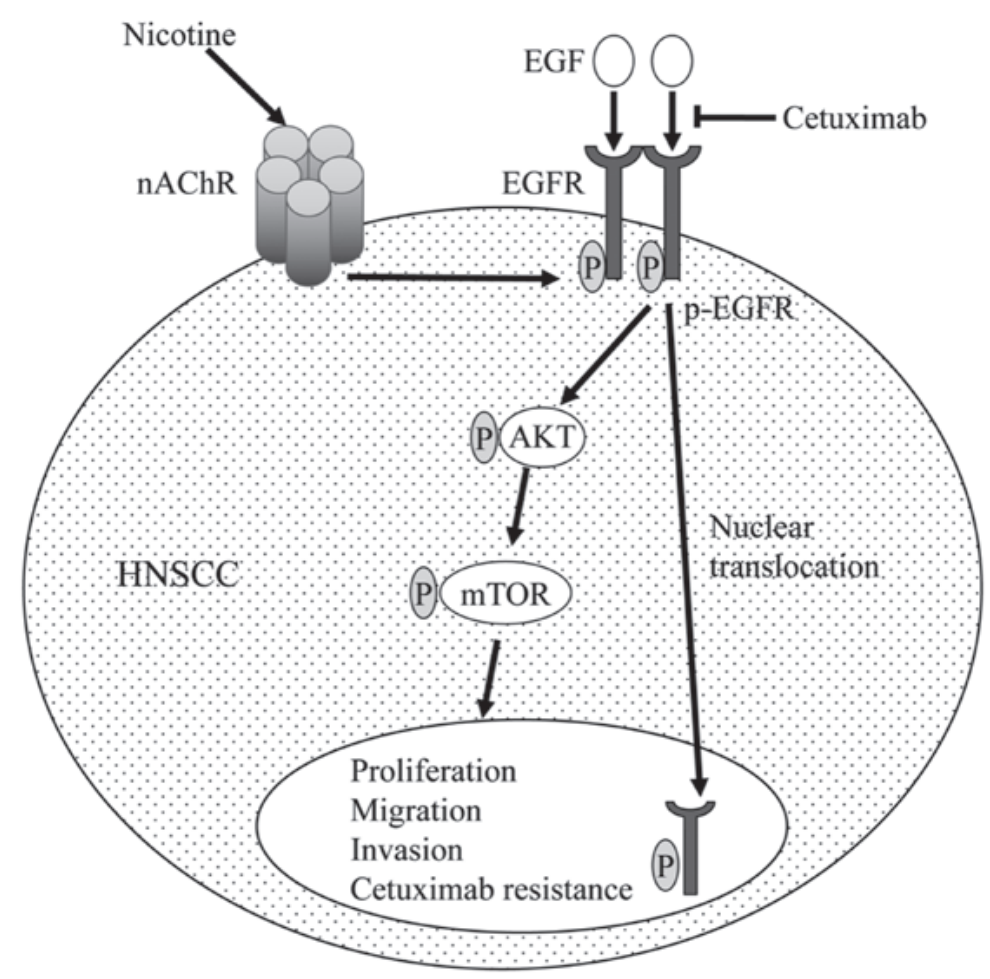

Figure 7. Function of nicotine in EGFR signaling in HNSCC. Nicotine binds to nAChR and enhances EGFR phosphorylation in HNSCC cells. EGFR phosphorylation elicits the Akt-mTOR pathway, a downstream signal transduction cascade, and p-EGFR itself is translocated to the nucleus, leading to cell proliferation, migration, invasion and cetuximab resistance. EGFR, epidermal growth factor receptor; HNSCC, head and neck squamous cell carcinoma cells; nAChR, nicotinic acetylcholine receptor; Akt, protein kinase B; mTOR, mechanistic target of rapamycin; EGF, epidermal growth factor; P, phosphate group.

experiments, in in vitro studies, cell proliferation, migration and invasion were significantly elevated in the nicotine-treated groups than the control groups in all four HNSCC cell lines. In the animal model, nicotine failed to induce lymphangiogenesis in tumor tissues (data not shown). This suggests that nicotine-induced lymphatic metastasis was attributable to nicotine-driven invasive cell activities. Conversely, MCA and $\alpha$-BTX, two nAChR inhibitors, reversed the nicotine-driven invasive cell activities, suggesting that nicotine stimulation of cell activities occurs through $n$ AChRs. The head and neck mucous epithelia express $\alpha 3, \alpha 5, \alpha 7, \alpha 9, \beta 2$ and $\beta 4$ nAChRs $(16,17)$. Among these nAChR subunits, $\alpha 7$ has been implicated as the most powerful nAChR subunit in terms of mediating the proliferative effects of nicotine in various cancer cells (18). Furthermore, nicotine activates $\alpha 7 \mathrm{nAChR}$ of keratinocytes in the head and neck region $(17,42,43)$. These findings indicate that nicotine accelerates cell activity of HNSCC cells via $\alpha 7 \mathrm{nAChR}$. This is consistent with the present in vitro finding that $\alpha$-BTX inhibited nicotine-increased cell proliferation, migration and invasion to the level of the control groups.

Cetuximab, a chimeric human mouse anti-EGFR monoclonal antibody, was the first molecular target drug used in head and neck cancer therapy $(7,8)$. In our experiments, nicotine induced phosphorylation and nuclear translocation of EGFR. Nuclear translocation of EGFR is correlated with worse prognosis of HNSCC (3). Cetuximab is known to inhibit EGFR translocation to the nucleus, while accumulation of intranuclear EGFR is known to have some relevance to cetuximab resistance (3). Nicotine may suppress the anti-tumor effect of cetuximab by promoting EGFR nuclear translocation. In the present experiments, nicotine restored the cetuximab-inhibited cell proliferation, migration and invasion of HNSCC cells. However, we note here that cetuximab resistance might also arise through another mechanism, since nicotine failed to restore the cetuximab-inhibited cell activities to the level seen in the untreated control groups.

In the in vitro experiments, cetuximab inhibited EGFR phosphorylation in HSC-3 cells. Conversely, cetuximab increased EGFR phosphorylation in OSC-19 cells, although Akt phosphorylation was still inhibited by cetuximab in this cell line. Recently, it was demonstrated that HNSCC secreted cetuximab with EGFR-containing extracellular vesicles $(44,45)$. OSC-19 cells may incorporate cetuximab-bound EGFR in the cytoplasm following EGFR phosphorylation, and the cetuximab-bound EGFR may be excluded by this novel mechanism.

To date, no study has examined the direct effect of nicotine on cetuximab sensitivity, to the best of our knowledge. However, a few studies have demonstrated the effect of nicotine on anti-EGFR cancer therapy. In non-small cell lung cancer, nicotine induces resistance to erlotinib and gefitinib, which are EGFR tyrosine kinase inhibitors $(23,46)$. In colorectal cancer, cigarette smoking during anticancer treatment with a cetuximab-based regimen reduces the therapeutic benefit (47). These findings support the present hypothesis that nicotine serves a role in cetuximab resistance. In addition, nicotine suppresses cisplatin-induced apoptosis in HNSCC cells through Akt signaling, which is a mandatory signaling pathway for cell survival and regulation 
of apoptosis (48). Akt regulates the expression of survivin, which inhibits apoptosis (48). In the present experiments, nicotine treatment induced phosphorylation of Akt and its downstream molecule mTOR. This suggests that MCA and $\alpha$-BTX inhibited Akt phosphorylation and that nicotine induced Akt phosphorylation through nAChRs. Furthermore. Akt inhibitor II and temsirolimus induced no changes in the expression or phosphorylation of EGFR, suggesting that the nicotine-driven Akt phosphorylation resides downstream of EGFR (Fig. 7).

In an in vivo experiment, cetuximab inhibited metastasis. However, nicotine failed to restore the cetuximab-inhibited metastasis. Therefore, the effect of nicotine in metastatic HNSCC treated with cetuximab remains unclear, and further investigation of this effect is required. In human papillomavirus-positive oropharyngeal cancer, increased distant metastases rates were noted in active smokers vs. never/former smokers (22 vs. 5\%), and cetuximab-based bio-radiotherapy (BRT) vs. cisplatin-based chemoradiotherapy (CRT) (23 vs. 5\%) (49). Although there was no difference in nodal disease extent between CRT and BRT groups in that previous study, nicotine and cetuximab may have synergistic negative effects in certain types of HNSCC.

In conclusion, nicotine induced the phosphorylation of EGFR through $\mathrm{nAChR}$ in the present experiments. Phosphorylated EGFR was translocated from the cell surface to the nucleus, and activated Akt and mTOR. These signaling pathways elevated the cell activities of HNSCC cells, causing lymph node metastasis and serving a role in cetuximab resistance (Fig. 7). Blockade of nicotine-nAChR signaling may be of clinical benefit in cases of advanced HNSCC, especially HNSCC in the oral cavity, which is the primary site of exposure to nicotine, by inhibiting lymph node metastasis and releasing cetuximab resistance.

\section{Acknowledgements}

The authors are grateful to Dr Takanori Tsuji (Department of Radiation Oncology, Beth Israel Deaconess Medical Center, Harvard Medical School, Boston, MA, USA) for suggesting the topic treated in this paper. The authors also thank Ms. Kazuko Funakoshi (Department of Oral Pathology and Medicine, Okayama University Graduate School of Medicine, Dentistry, and Pharmaceutical Sciences, Okayama, Japan) for the expert technical assistance in histological preparations.

\section{Funding}

The present study was supported by a Grant-in-Aid for Scientific Research (B) (JSPS KAKENHI grant no. JP 17H04405) to AS, a Grant-in-Aid for Scientific Research (C) (JSPS KAKENHI grant no. JP 26463004, 17K11836) from the Ministry of Education, Culture, Sports, Science, and Technology of Japan to SI and a Wesco Scientific Promotion Foundation Grant to SI.

\section{Availability of data and materials}

The datasets used and analyzed during the current study are available from the corresponding author on reasonable request.

\section{Authors' contributions}

SI and AS conceptualized and designed the study. AS, SI, TE, HN, KOk, RS, DK, SK and TN prepared resources and devised methodology. RS, DK, SK, TN, TO KOb, KT, HK, KOn and KOk carried out the experimentation. SI, TE, RS, DK, SK and TN interpreted data. SI wrote the manuscript. AS, $\mathrm{HN}, \mathrm{KOk}, \mathrm{TE}$ and SI revised and edited the manuscript. All authors reviewed the manuscript.

\section{Ethics approval and consent to participate}

All animal experiments were approved by the Institutional Animal Care and Use Committee of Okayama University (Okayama, Japan; OKU-2016046).

\section{Patient consent for publication}

Not applicable.

\section{Competing interests}

The authors declare that they have no competing interests.

\section{References}

1. Cohen $\mathrm{S}$ : Isolation of a mouse submaxillary gland protein accelerating incisor eruption and eyelid opening in the new-born animal. J Biol Chem 237: 1555-1562, 1962.

2. Avraham R and Yarden Y: Feedback regulation of EGFR signalling: Decision making by early and delayed loops. Nat Rev Mol Cell Biol 12: 104-117, 2011.

3. Burtness B, Bauman JE and Galloway T: Novel targets in HPV-negative head and neck cancer: Overcoming resistance to EGFR inhibition. Lancet Oncol 14: e302-e309, 2013.

4. Nicholson RI, Gee JM and Harper ME: EGFR and cancer prognosis. Eur J Cancer 37 (Suppl 4): S9-S15, 2001.

5. Selvaggi G, Novello S, Torri V, Leonardo E, De Giuli P, Borasio P, Mossetti C, Ardissone F, Lausi P and Scagliotti GV: Epidermal growth factor receptor overexpression correlates with a poor prognosis in completely resected non-small-cell lung cancer. Ann Oncol 15: 28-32, 2004.

6. Hirsch FR, Varella-Garcia M, Bunn PA Jr, Di Maria MV, Veve R, Bremmes RM, Barón AE, Zeng C and Franklin WA: Epidermal growth factor receptor in non-small-cell lung carcinomas: Correlation between gene copy number and protein expression and impact on prognosis. J Clin Oncol 21: 3798-3807, 2003.

7. Bonner JA, Harari PM, Giralt J, Azarnia N, Shin DM, Cohen RB Jones CU, Sur R, Raben D, Jassem J, et al: Radiotherapy plus cetuximab for squamous-cell carcinoma of the head and neck. N Engl J Med 354: 567-578, 2006.

8. Vermorken JB, Mesia R, Rivera F, Remenar E, Kawecki A, Rottey S, Erfan J, Zabolotnyy D, Kienzer HR, Cupissol D, et al: Platinum-based chemotherapy plus cetuximab in head and neck cancer. N Engl J Med 359: 1116-1127, 2008.

9. Wheeler DL, Dunn EF and Harari PM: Understanding resistance to EGFR inhibitors-impact on future treatment strategies. Nat Rev Clin Oncol 7: 493-507, 2010.

10. International Agency for Research on Cancer (IARC): IARC Working Group on the Evaluation of Carcinogenic Risks to Humans. Tobacco smoke and involuntary smoking. IARC Work Gr Eval Carcinog Risks Hum 83: 1-1438, 2004.

11. Valavanidis A, Vlachogianni T and Fiotakis K: Tobacco smoke: Involvement of reactive oxygen species and stable free radicals in mechanisms of oxidative damage, carcinogenesis and synergistic effects with other respirable particles. Int J Environ Res Public Health 6: 445-462, 2009.

12. Benowitz NL: Neurobiology of nicotine addiction: Implications for smoking cessation treatment. Am J Med 121 (Suppl 1): S3-S10, 2008. 
13. Sanner T and Grimsrud TK: Nicotine: Carcinogenicity and effects on response to cancer treatment - A review. Front Oncol 5: 196, 2015.

14. Davis R, Rizwani W, Banerjee S, Kovacs M, Haura E, Coppola D and Chellappan S: Nicotine promotes tumor growth and metastasis in mouse models of lung cancer. PLoS One 4: e7524, 2009.

15. Egleton RD, Brown KC and Dasgupta P: Nicotinic acetylcholine receptors in cancer: Multiple roles in proliferation and inhibition of apoptosis. Trends Pharmacol Sci 29: 151-158, 2008.

16. Nguyen VT, Hall LL, Gallacher G, Ndoye A, Jolkovsky DL, Webber RJ, Buchli R and Grando SA: Choline acetyltransferase, acetylcholinesterase, and nicotinic acetylcholine receptors of human gingival and esophageal epithelia. J Dent Res 79: 939-949, 2000.

17. Arredondo J, Chernyavsky AI, Jolkovsky DL, Pinkerton KE and Grando SA: Receptor-mediated tobacco toxicity: Cooperation of the Ras/Raf-1/MEK1/ERK and JAK-2/STAT-3 pathways downstream of alpha7 nicotinic receptor in oral keratinocytes. FASEB J 20: 2093-2101, 2006.

18. Schuller HM: Is cancer triggered by altered signalling of nicotinic acetylcholine receptors? Nat Rev Cancer 9: 195-205, 2009.

19. Nishioka T, Guo J, Yamamoto D, Chen L, Huppi P and Chen CY: Nicotine, through upregulating pro-survival signaling, cooperates with NNK to promote transformation. J Cell Biochem 109: 152-161, 2010.

20. Guo J, Ibaragi S, Zhu T, Luo LY, Hu GF, Huppi PS and Chen CY: Nicotine promotes mammary tumor migration via a signaling cascade involving protein kinase $\mathrm{C}$ and CDC42. Cancer Res 68: 8473-8481, 2008.

21. Ye YN, Liu ESL, Shin VY, Wu WKK, Luo JC and Cho CH: Nicotine promoted colon cancer growth via epidermal growth factor receptor, c-Src, and 5-lipoxygenase-mediated signal pathway. J Pharmacol Exp Ther 308: 66-72, 2004.

22. Nishioka T, Kim HS, Luo LY, Huang Y, Guo J and Chen CY: Sensitization of epithelial growth factor receptors by nicotine exposure to promote breast cancer cell growth. Breast Cancer Res 13: R113, 2011.

23. Li H, Wang S, Takayama K, Harada T, Okamoto I, Iwama E, Fujii A, Ota K, Hidaka N, Kawano Y, et al: Nicotine induces resistance to erlotinib via cross-talk between $\alpha 1 \mathrm{nAChR}$ and EGFR in the non-small cell lung cancer xenograft model. Lung Cancer 88: 1-8, 2015.

24. Wang S, Takayama K, Tanaka K, Takeshita M, Nakagaki N, Ijichi K, Li H and Nakanishi Y: Nicotine induces resistance to epidermal growth factor receptor tyrosine kinase inhibitor by a1 nicotinic acetylcholine receptor-mediated activation in PC9 cells. J Thorac Oncol 8: 719-725, 2013.

25. Zhao W, Yan J, Gao L, Zhao J, Zhao C, Gao C, Luo X and Zhu X: Cdk5 is required for the neuroprotective effect of transforming growth factor- $\beta 1$ against cerebral ischemia-reperfusion. Biochem Biophys Res Commun 485: 775-781, 2017.

26. Zhang S, Deng Z, Yao C, Huang P,Zhang Y, Cao S and Li X: AT7867 Inhibits human colorectal cancer cells via AKT-dependent and AKT-independent mechanisms. PLoS One 12: e0169585, 2017.

27. von Roemeling CA, Marlow LA, Kennedy WP, Kennedy GT, Copland JA and Menefee ME: Preclinical evaluation of the mTOR inhibitor, temsirolimus, in combination with the epothilone B analog, ixabepilone in renal cell carcinoma. Am J Cancer Res 3: 390-401, 2013

28. Minna JD: Nicotine exposure and bronchial epithelial cell nicotinic acetylcholine receptor expression in the pathogenesis of lung cancer. J Clin Invest 111: 31-33, 2003.

29. Heusch WL and Maneckjee R: Signalling pathways involved in nicotine regulation of apoptosis of human lung cancer cells. Carcinogenesis 19: 551-556, 1998.

30. Kurai J, Chikumi H, Hashimoto K, Takata M, Sako T, Yamaguchi K, Kinoshita $N$, Watanabe $M$, Touge $H$, Makino $\mathrm{H}$, et al: Therapeutic antitumor efficacy of anti-epidermal growth factor receptor antibody, cetuximab, against malignant pleural mesothelioma. Int J Oncol 41: 1610-1618, 2012.

31. Takada H, Ibaragi S, Eguchi T, Okui T, Obata K, Masui M, Morisawa A, Takabatake K, Kawai H, Yoshioka N, et al: Semaphorin 4D promotes bone invasion in head and neck squamous cell carcinoma. Int J Oncol 51: 625-632, 2017.
32. Harrell MI, Iritani BM and Ruddell A: Tumor-induced sentinel lymph node lymphangiogenesis and increased lymph flow precede melanoma metastasis. Am J Pathol 170: 774-786, 2007.

33. Bagdas D, Meade JA, Alkhlaif Y, Muldoon PP, Carroll FI and Damaj MI: Effect of nicotine and alpha-7 nicotinic modulators on visceral pain-induced conditioned place aversion in mice. Eur J Pain: Apr 10, 2018 (Epub ahead of print). doi: 10.1002/ejp.1231.

34. Wild R, Fager K, Flefleh C, Kan D, Inigo I, Castaneda S, Luo FR, Camuso A, McGlinchey K and Rose WC: Cetuximab preclinical antitumor activity (monotherapy and combination based) is not predicted by relative total or activated epidermal growth factor receptor tumor expression levels. Mol Cancer Ther 5: 104-113, 2006.

35. Shibata T, Kan H, Murakami Y, Ureshino H, Watari K, Kawahara A, Kage M, Hattori S, Ono M and Kuwano M: Y-box binding protein-1 contributes to both HER2/ErbB2 expression and lapatinib sensitivity in human gastric cancer cells. Mol Cancer Ther 12: 737-746, 2013.

36. Matsui T, Ota T, Ueda Y, Tanino M and Odashima S: Isolation of a highly metastatic cell line to lymph node in human oral squamous cell carcinoma by orthotopic implantation in nude mice. Oral Oncol 34: 253-256, 1998.

37. Chikamatsu K, Reichert TE, Kashii Y, Saito T, Kawashiri S, Yamamoto E and Whiteside TL: Immunotherapy with effector cells and IL-2 of lymph node metastases of human squamous-cell carcinoma of the head and neck established in nude mice. Int J Cancer 82: 532-537, 1999.

38. Nickell JR, Grinevich VP, Siripurapu KB, Smith AM and Dwoskin LP: Potential therapeutic uses of mecamylamine and its stereoisomers. Pharmacol Biochem Behav 108: 28-43, 2013.

39. Shytle RD, Penny E, Silver AA, Goldman J and Sanberg PR: Mecamylamine (Inversine): An old antihypertensive with new research directions. J Hum Hypertens 16: 453-457, 2002.

40. Young HS, Herbette LG and Skita V: $\alpha$-bungarotoxin binding to acetylcholine receptor membranes studied by low angle X-ray diffraction. Biophys J 85: 943-953, 2003.

41. Dasgupta P, Rizwani W, Pillai S, Kinkade R, Kovacs M, Rastogi S, Banerjee S, Carless M, Kim E, Coppola D, et al: Nicotine induces cell proliferation, invasion and epithelial-mesenchymal transition in a variety of human cancer cell lines. Int J Cancer 124: 36-45, 2009.

42. Wang C, Niu W, Chen H, Shi N, He D, Zhang M, Ge L, Tian Z, Qi M, Chen T, et al: Nicotine suppresses apoptosis by regulating $\alpha 7 \mathrm{nAChR} /$ Prx1 axis in oral precancerous lesions. Oncotarget 8: 75065-75075, 2017.

43. Arredondo J, Chernyavsky AI and Grando SA: Nicotinic receptors mediate tumorigenic action of tobacco-derived nitrosamines on immortalized oral epithelial cells. Cancer Biol Ther 5: 511-517, 2006.

44. Fujiwara T, Eguchi T, Sogawa C, Ono K, Murakami J, Ibaragi S, Asaumi JI, Okamoto K, Calderwood SK and Kozaki KI: Anti-EGFR antibody cetuximab is secreted by oral squamous cell carcinoma and alters EGF-driven mesenchymal transition. Biochem Biophys Res Commun 503: 1267-1272, 2018.

45. Ono K, Eguchi T, Sogawa C, Calderwood SK, Futagawa J, Kasai T, Seno M, Okamoto K, Sasaki A and Kozaki KI: HSP-enriched properties of extracellular vesicles involve survival of metastatic oral cancer cells. J Cell Biochem 119: 7350-7362, 2018.

46. Togashi Y, Hayashi H, Okamoto K, Fumita S, Terashima M, de Velasco MA, Sakai K, Fujita Y, Tomida S, Nakagawa K, et al: Chronic nicotine exposure mediates resistance to EGFR-TKI in EGFR-mutated lung cancer via an EGFR signal. Lung Cancer 88: 16-23, 2015.

47. Kajizono M, Saito M, Maeda M, Yamaji K, Fujiwara S, Kawasaki Y, Matsunaga $\mathrm{H}$ and Sendo T: Cetuximab-induced skin reactions are suppressed by cigarette smoking in patients with advanced colorectal cancer. Int J Clin Oncol 18: 684-688, 2013.

48. Xu J, Huang H, Pan C, Zhang B, Liu X and Zhang L: Nicotine inhibits apoptosis induced by cisplatin in human oral cancer cells. Int J Oral Maxillofac Surg 36: 739-744, 2007.

49. Weller MA, Ward MC, Berriochoa C, Reddy CA, Trosman S, Greskovich JF, Nwizu TI, Burkey BB, Adelstein DJ and Koyfman SA: Predictors of distant metastasis in human papillomavirus-associated oropharyngeal cancer. Head Neck 39: 940-946, 2017. 